Manuscript Number: JCLEPRO-D-16-01409R3

Title: Assessing the level of collaboration in the Egyptian organic and fair trade cotton chain

Article Type: SI:Bio-economy paths for CP

Keywords: supply chain collaboration, factor analysis, organic, fair trade, Sekem, Egypt

Corresponding Author: Dr. Cosimo Rota,

Corresponding Author's Institution: Alma Mater Studiorum - University of Bologna

First Author: Cosimo Rota

Order of Authors: Cosimo Rota; Patrizia Pugliese; Shadi Hashem; Cesare Zanasi

Abstract: There is rising interest in collaboration among supply chain partners in food and fibre supply chain management studies. In organic and fair-trade chains, collaboration is rooted in both principles and current practices. A tool for assessing collaboration in the food and fibre sector has not been developed to date. To fill this gap a collaboration index has been adapted to the Egyptian organic and fair trade cotton supply chain. A factor analysis has been performed to this end. Two factors emerged within each of the three constructs defining the collaboration index: information sharing (price information and logistics), decision synchronization (exception management and general management) incentive alignment (risk sharing and technical support). The study contributes to defining a method for designing specific collaboration indexes in different food and fibre chains. The index provided relevant context-related information supporting the collaboration strategies in the Egyptian organic cotton chain. 


\title{
Highlights
}

- A method for designing collaboration indexes in food and fibre chains is defined

- The index refers to decision synchronization, information sharing, incentive alignment

- Six distinct factors were extracted across the three dimensions of collaboration

- The collaboration between the lead company and the contracted farmers is described

- The index indicates how to implement effective collaborative strategies

\section{Assessing the level of collaboration in the Egyptian organic and fair trade cotton chain}

\begin{abstract}
There is rising interest in collaboration among supply chain partners in food and fibre supply chain management studies. In organic and fair-trade chains, collaboration is rooted in both principles and current practices. A tool for assessing collaboration in the food and fibre sector has not been developed to date. To fill this gap a collaboration index has been adapted to the Egyptian organic and fair trade cotton supply chain. A factor analysis has been performed to this end. Two factors emerged within each of the three constructs defining the collaboration index: information sharing (price information and logistics), decision synchronization (exception management and general management) incentive alignment (risk sharing and technical support). The study contributes to defining a method for designing specific collaboration indexes in different food and fibre chains. The index provided relevant context-related information supporting the collaboration strategies in the Egyptian organic cotton chain.
\end{abstract}

Keywords: supply chain collaboration, factor analysis, organic, fair trade, Sekem, Egypt.

\section{Introduction}

The current debate on innovative and sustainable models of production and consumption considers, among other issues, the necessity of introducing new ways to assess businesses performances and success (Blok et al., 2015). The dimension of sustainability in business management is addressed by the Sustainability Oriented Theory of the Firm, which states that "the firm is a profit generating entity in a state of constant evolution. This entity is a system comprised of resources and networks of relationships with stakeholders" (Lozano et al., 2015). The same authors also state the necessity to provide "a firm's leaders and its stakeholders with a more complete vision of their obligations, opportunities, relationships, and processes...to make societies become more sustainable in the short and long term" (Lozano et al., 2015). Improving the stakeholders' relationships, by assessing the level of collaboration between supply chain partners, as a driver of effective sustainability management, can thus represent a relevant contribution to the debate on sustainable models of production. Collaboration has recently received increased attention in the supply chain literature; an increasing number of enterprises recognize the importance of working and operating together to resolve common problems and achieve desired goals (Barratt, 2004; Corbett et al., 1999; Schöggl et al., 2016; Seliger et al., 2015; Wagner et al., 2002). Collaboration is also viewed as a business process whereby collaborative partners work together toward common goals that mutually benefit the partnering firms (Mentzer et al., 2008). Several authors argue that a supply chain agent's ability to compete is strongly related to its ability to collaborate with suppliers at various levels in the chain as a way to construct more efficient and responsive supply chains (Christopher, 2005; Gunasekaran and Patel, 2001; Lamming, 1993). In particular, the benefits associated with closer collaboration, according to Lee et al. (2007), involve cost reductions and revenue enhancements as well as flexibility when dealing with supply and demand uncertainties. Crook et al. (2008) refer to 
collaboration as a long-term, win-win, open information exchange type of agreement in which both and dispute resolution.

This concept implies that chain actors are involved in coordinating activities that span the boundaries of their organizations (Bowersox et al., 2003; Mentzer et al., 2000).

The dimensions defining chain collaboration include joint decision making and joint problem solving, natural extensions of sharing information among independent supply chain partners (Spekman and Carraway, 2006).

According to Simatupang and Sridharan (2005), supply chain collaboration is defined as "two or more chain members working together to create a competitive advantage through sharing information, making joint decisions, and sharing benefits which result from greater profitability of satisfying end customer needs than acting alone".

Cao and Zhang (2010) defined supply chain collaboration as "a partnership process where two or more autonomous firms work closely to plan and execute supply chain operations towards common goals and mutual benefits". The same authors, based on a large literature survey, expand Simatupang and Sridharan's approach (2005) by developing a measurement instrument interconnecting seven dimensions: information sharing, goal congruence, decision synchronization, resource sharing, incentive alignment, collaborative communication and joint knowledge creation among independent supply chain partners.

The link between collaboration and sustainability in managing the supply chain has been emphasized by recent studies analysing the critical contribution of collaboration between supply chains (SC) actors in building sustainable supply chains (SSCs).

Seuring and Müller (2008) define sustainable supply chains as "the management of material, information and capital flows as well as of cooperation among companies along the supply chains while taking goals from all three dimensions of sustainable development, i.e., economic, environmental and social, into account which are derived from customer and stakeholder requirements". Touboulic and Walker (2015) also suggest that SSCM needs to integrate multiple dimensions and manage complex relations, rethinking relationship-management strategies to accommodate changes driven by sustainability needs (Pagell and Shevchenko, 2014; Touboulic and Walker, 2015).

Collaboration is promoted by transformational leadership, which not only involves suppliers in sustainability initiatives but also fosters different parties to participate, exchange views and work intensely with their suppliers to make them 'capable' and adopt new procurement thinking (Fadeeva, 2005; Govindan, n.d.; Govindan et al., 2016; Grekova et al., 2016, 2015; Kumar and Rahman, 2016; Porter and Kramer, 2011; Ramanathan et al., 2014; Riopelle et al., 2010; Rota et al., 2013; Sancha et al., 2016; Van Hoof and Thiell, 2014). Along the same stream of reasoning, in a discussion of their SSMC model, Gold et al. (2013) point out that to enhance sustainability performance, the first obvious stage of considering SSC sustainability needs to be followed by other steps. First, the supply chain design and operation have to be reconceptualised "to include (and leverage) skills and abilities of a broader scope of non-traditional actors", including NGOs and local communities (Van Hoof and Thiell, 2014). A second important step is "decommoditisation", which entails moving suppliers beyond commodity supplier status "by offering long-term partnership, paying above-market prices and engage in supplier development and education" (Gold et al., 2013; Pagell and Shevchenko, 2014). All this clearly embraces downstream and upstream collaboration within the chain and demands for adequate measurement of success.

It is also worth highlighting that the contexts influencing collaboration in sustainable supply chains may be different in developing countries and emerging economies because of diverse systemic barriers, such as infrastructural and institutional gaps and high social pressures (Silvestre, 2015). In the agricultural sector, integrating smallholders and poor rural communities into productive processes and international supply chains represents a crucial goal in SSCM (Fayet and Vermeulen, 2014; Gold et al., 2013). Within this context, Perez-Aleman and Sandilands (2008) state that poor 
producers require an 'active assistance approach' from companies, NGOs and the government to effectively support and upgrade the technical and cultural change toward sustainability.

Such additional context-related challenges expand the scope for further academic research on SSCM (Pagell and Shevchenko, 2014) and, more specifically, on the measurement of sustainable supply chains collaboration (SSCC).

Organic and fair trade commodities produced in developing countries offer a good case study for analysing the performance of collaborative relationships within food and fibres chains in developing countries. Organic production and fair trade involve collaboration between the chains' agents in terms of transparency, sharing information on technical and managerial practices and, in particular for fair trade, contractual agreements related to defining prices. Following Kottila and Rönni (2008), small organic farmers can and should be involved in trustful and collaborative relationships with other chain agents.

Furthermore, organic, fair trade, and in general sustainable cotton chains increasingly play an interesting role in many developing countries' economic development, also heavily influencing sustainable social and environmental development in the areas where cotton is grown.

Egypt represents a major player in organic cotton; it has a long-standing reputation in the production of extra-long staple cotton and is one of the top ten organic cotton-growing countries in the world (Textile Exchange, 2015). Most activities in the Egyptian organic cotton sector appear to revolve around a leading actor, NaturTex, one of the four subsidiary companies of Sekem Holding 1 . As a consequence, the relationships between farmers and leading companies in the Egyptian organic and fair trade cotton chains can provide a relevant field for analysing collaboration within food and fibre chains in developing countries.

The only two existing analyses of organic food chain collaboration have been developed by Kottila and Rönni (2008) and by Naspetti et al., (2011). The former adopts a qualitative approach based on in-depth interviews and investigates the relationship between collaboration and trust, and the latter defines a quantitative collaboration index based on Simatupang and Sridharan's approach (2005b) applied to organic sector collaboration in the EU and considers the relationship between collaboration and chains' performance.

A more extensive set of items and collaboration dimensions is provided by Cao and Zhang (2010) who define seven dimensions and 35 items. This represents the most comprehensive conceptual framework available, and it can be adopted to monitor the collaborative performance of an organic and fair trade chain.

Developments in studies on collaboration should consider indicators tailored to the different contexts to which they are applied, for instance, the definition of items more clearly related to the different contexts. In particular, considering the importance of collaboration within the organic chains in developing countries (Kristiansen et al., 2006), a study adapting the collaboration index to these specific sectors represents an interesting contribution to the development of sustainable organic and fair trade food and fibre chains.

The need to adapt the collaboration index items and dimension to a specific context calls for an explorative procedure through a specific statistical method such as an explorative factor analysis; the items and dimensions should be tested to assess the consistence of the theoretical construct to the emerging factors.

This process can provide relevant integration to the sustainability analysis of food and fibre chains. Despite its important instrumental contribution to the building of SSCs, collaboration between actors is not explicitly considered in sustainability assessment frameworks currently adopted by public institutions and private companies.

The potential extremely wide range of variables and the associated costs involved in the collaborative index assessment approach adopted could make its implementation and the consequent definition of strategies, too complex and/or expensive.

\footnotetext{
${ }^{1}$ http://www.sekem.com/
} 
The present study aims to support the definition of efficient and effective sustainable and collaborative chain assessment and strategies. To this end, a collaboration index is developed as a monitoring tool for assessing the level and characteristics of collaboration between farmers and chain leaders, the focus being on the organic and fair trade cotton chain in Egypt. An interesting example of how a collaboration index can be relevant within this context is represented by the Egyptian organic and fair trade cotton supply chain (NaturTex), which belongs to the mother company Sekem, a pioneer of organic agriculture in Egypt.

Founded in 1977 with the goal of attaining sustainable human development, the Sekem landmark initiative is one of the pioneers and leading champions of organics in the whole south-eastern Mediterranean region. NaturTex was established in 1998. It produces high-quality organic textiles and garments, overseeing - directly or through sub-contractors - the whole supply chain, from cotton cultivation to the marketing of more than thirty different $100 \%$ organic finished products, which are mainly exported and partially sold in Egypt, under the company's own brand as well as under other private labels. The final stages of cutting, sewing, and packaging are managed at the company's factory, whereas the previous processing steps are carried out by different Global Organic Textile Standard (GOTS) certified subcontractors. With seasonal contracts signed in the framework of a long-term partnership and over five hundred out-growers located in the region of the Nile Delta and the Fayoum governorate, supply organic cotton is produced according to biodynamic standards (Textile Exchange, 2015). In areas where producers farm very small plots, group certification arrangements are established and one leader producer operationally manages commercial relations with the lead company. Through a dense network of local experts, the company provides continuous technical and financial support to its suppliers throughout the cotton cultivation cycle. This leads to a complex and multifaceted relationship with its farmers, making this chain particularly suitable to a supply chain collaboration analysis.

\section{Materials and Methods}

The method adopted to measure the chain collaboration index involves four interrelated steps, as shown in table 1.

Table 1. Overview of the four methodological steps

\begin{tabular}{|c|c|c|c|}
\hline & STEPS & CONTENT & METHOD \\
\hline & CONCEPTUALIZATION & $\begin{array}{l}\text { Develop the theoretical } \\
\text { framework (constructs) }\end{array}$ & Literature review \\
\hline \multirow{2}{*}{2.2} & \multirow{2}{*}{ SCALE DEVELOPMENT } & $\begin{array}{l}\text { Generate items and define the } \\
\text { questionnaire }\end{array}$ & $\begin{array}{l}\text { Literature review } \\
\text { Researcher' } \\
\text { hypothesis }\end{array}$ \\
\hline & & $\begin{array}{l}\text { Assess the content validity of } \\
\text { the items }\end{array}$ & Expert panel \\
\hline 2.3 & DATA COLLECTION & Collect quantitative data & $\begin{array}{l}\text { Structured } \\
\text { interview }\end{array}$ \\
\hline \multirow{3}{*}{2.4} & \multirow{3}{*}{ SCALE EVALUATION } & Reduce the items & \multirow{2}{*}{ Factor Analysis } \\
\hline & & Assess the construct validity & \\
\hline & & Assess the reliability & Cronbach's alpha \\
\hline
\end{tabular}




\subsection{Model construct}

This study adopts Simatupang and Sridharan's approach (2005) to the construction of a "collaboration index". This quantitative index of collaboration uses three dimensions: decision synchronization, information sharing and incentive alignment. This represents a more feasible approach when compared to Cao and Zhang's seven conceptual dimensions.

The smaller number of conceptual dimensions and related items involved in the present collaboration index consider the necessity to provide a monitoring tool, which should be both effective and efficient, allowing different users to implement it and understand the outcomes, especially in a developing country rural context.

In particular, the dimension information sharing aims to capture and disseminate timely and relevant information, enabling decision makers to plan and control supply chain operations. Effective information sharing enables chain members to address product flow issues more quickly, which permits more agile demand planning. Several criteria, such as relevancy, accuracy, timeliness, and reliability, can be used to judge the contribution of information sharing to supply chain integration (Sheu et al., 2006; Simatupang and Sridharan, 2005).

Decision synchronization refers to joint decision making in the planning and operational stage. These joint decisions are used to guide logistical processes among supply chain members. The planning stage integrates decisions about long-term planning and measures such as selecting target markets, choosing the customer service level and forecasting (Simatupang and Sridharan, 2004). Effective decision synchronization is judged based on its effects on accurate response towards fulfilling customer demands (i.e., logistical benefits) and supply chain profitability (i.e., commercial benefits) (Corbett et al., 1999).

Incentive alignment refers to the process of sharing costs, risks, and benefits among the participating members (Simatupang and Sridharan, 2002). It motivates the members to act in a manner consistent with their mutual strategic objectives, including making decisions that are optimal for the overall supply chain and revealing truthful private information. It covers calculating costs, risks, and benefits as well as formulating incentive schemes, such as pay-for-performance and pay-for-effort (Simatupang and Sridharan, 2005).

As mentioned above, to define an effective measurement of chain collaboration and adapt the collaboration index measurement tool by testing how it works in different contexts, it is necessary to:

1. gain a clear understanding of the context for defining the new item statements and dimensions of the adopted instrument and

2. assess and describe the theoretical framework and different dimensions and items that define the collaboration index.

This study contributes to the refinement of this approach by adapting, modifying and adding more items to the collaboration index to reflect and capture the context of the organic and fair trade cotton sector in Egypt (see appendix A-B).

\subsection{Scale development}

The generation of measurement items for each construct took into consideration previous research on supply chain collaboration (Bowersox et al., 2003; Poirier, 1999; Ramdas and Spekman, 2000). As previously stated, integrations and refinements have been made to the items from the literature to make sure that they fit and are able to define collaboration in the given context (organic and fair trade cotton chain in Egypt) (see Appendix B).

From this process, 20 items were created for three dimensions of supply chain collaboration (information sharing, decision synchronization, incentive alignment) supporting the definition of a questionnaire whose items are summarized in table 2. The questionnaire contains a total of 34 questions translated into Arabic. All the questions are measured based on a five-point Likert scale ranging from Never (1) to Every time (5) (See Appendix B). 
During item construction, a panel of experts (practitioners, academics, and company managers) was consulted to verify that the operational definitions matched the theoretical concepts, making sure that the items fit the theoretical concepts adequately. After the first draft of the questionnaire was defined, the same panel was asked to identify ambiguous items, poorly worded questions, and poor instructions for answering the questionnaire. The panel found no major problems with the response format, directions, or other procedures involved in the survey.

Table 2. Items statements compiled to define a collaboration measurement instrument

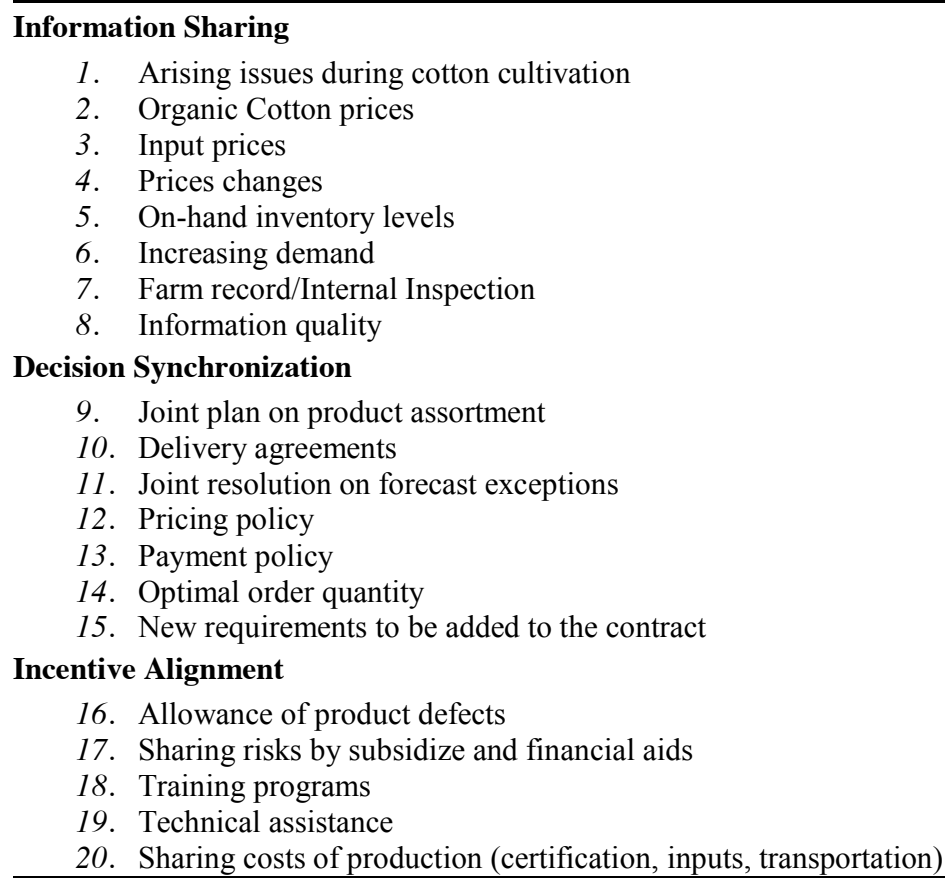

\subsection{Data collection}

Before the beginning of the study, a face-to-face meeting was held to inform the company about the study and the importance of their participation and contribution. Then, to be able to design the company's value chain, official documents (contracts, clauses) describing the relation between the company and farmers were collected. This contributed not only to the general description of the context of the analysis and of the chain structure but also supported fieldwork in Egypt in terms of data collection at the farmer level.

The interviews were conducted in March-April 2013 in Egypt, in the governates of El-Behera, ElFayoum, El-Dakahlya, EL-Kalyoubya, and El-Sharkya, where the company NaturTex and the contracted farmers were located. Prior to the interviews, a pre-testing of the questionnaire and the scaling was performed on the field, with researchers contacting one small-scale farmer and one large-scale farmer. The viability of the questions and the scales and the questionnaire clarity were checked. A total of 16 complete questionnaires were collected out of 25 farmers contacted. The farmers answered not only for their own farms but also for most of the entities constituting the whole of farmers supplying NaturTex. It must be remembered that during the preparation of the fieldwork, a local contact in Egypt (Sekem managers) explained that the relations between NaturTex and the suppliers are mediated by farmers representing the different entities. They were chosen as respondents (statistical unit) because they are the only ones able to answer questions related to relationships with the leading company of the chain (NaturTex). The respondents are proportionally distributed in the different areas of production and in each area; they represent at least $50 \%$ of farmers. Consequently, even if the sample is numerically small, it can be considered as representative of farmers' views on collaboration. 
All farmers and the company representatives were interviewed face-to-face. Before beginning, an explanation of the purpose of the interview and the intended uses of the information and assurances of confidentiality were given. During the interview, complementary notes were taken and developed immediately after each interview to ensure accuracy. If needed, the respondents' doubts were discussed and resolved during the interview. Each interview with the farmers took between 45 minutes and one hour.

\subsection{Scale evaluation}

After the data collection, the validation of the scales was performed. Reliability measures and factor analysis were used to this end (Hinkin, 1995). The issue of which particular method of factor analysis should be used in this process has been addressed in several studies (Hensley, 1999). While confirmatory factor analysis (CFA) is used to test the hypothesized and predetermined scale structure, exploratory factor analysis (EFA) is used to extract sets of factors from the questions when the scale structure is not hypothesized (Spector, 1992).

As above reported, the need to adapt the collaboration index items and dimension to a specific context calls for an explorative procedure in order to assess the consistence of the adapted items and dimensions to the emerging factors.

Exploratory factor analysis (EFA) was conducted to determine what items or scales should be included in a measure and what items to discard when they did not load on the appropriate component of the dimensions of supply chain collaboration. In addition, some modifications were made to the original construct formulations based on the total variance of each item. The EFA was also performed to assess the validity of the multidimensional construct of collaboration identifying the number of underlying factors structure. Finally, the Cronbach's alpha index was used to assess the reliability and overall consistency of the measurement scale. EFA is used to discover the number of factors influencing variables and to analyse which variables "go together" (DeCoster, 1998). A basic hypothesis of EFA is that there are $m$ common 'latent' factors to be discovered in the dataset, and the goal is to find the smallest number of common factors that will account for the correlations (McDonald, 2014). The factor analysis model can be written algebraically as follows. Having $p$ variables $X 1, X 2, \ldots, X p$ measured on a sample of $n$ subjects, variable $i$ can be written as a linear combination of $m$ factors $F 1, F 2, \ldots, F m$ where, as explained above, $m<p$. Thus,

$$
\mathrm{Xi}=\mathrm{ai} 1 \mathrm{~F} 1+\mathrm{ai} 2 \mathrm{~F} 2+\ldots+\operatorname{aimFm}+\mathrm{ei}
$$

where $a i$ is the factor loadings (or score) for variable $i, e i$ is the part of variable $X i$ that cannot be explained by the factors.

Factor analysis uses matrix algebra when computing its calculations. The basic statistic used in factor analysis is the correlation coefficient, which determines the relationship between two variables. The researcher examines if variables have some features in common and then computes a correlation or covariance matrix (Rummel, 1988). The factor loadings indicate how much the item has contributed to the factor; the larger the factor loading, the more the item contributed to that factor. Factor loading are very similar to weights in multiple regression analysis, and they represent the strength of the correlation between the item and the factor (Kline, 2014). The communalities reflect the variance of an item in common with all other together.

The factor analysis literature includes a range of recommendation about the issue of the minimum sample size. According to Henson and Roberts (2006) "sample size rules of thumb fail to take into account many of the complex dynamics of a factor analysis". MacCallum et al. (1999) demonstrate that the adequacy of a sample size depends in large part to the features of the obtained data, which means that definitive a priori decisions about sample size can be difficult. The authors also illustrate that when communalities are high (greater than .60), sample sizes can be relatively small. Moreover, de Winter et al. (2009) offer a comprehensive overview of the conditions in which EFA can yield good quality results for small samples, showing that when the data are well conditioned 
(i.e., high loadings, low factors, high communalities), EFA can yield reliable solutions for sample

\section{Findings}

\subsection{Descriptive statistics}

A collaboration index was measured to assess the ability of the modified index in capturing the collaboration aspects between NaturTex and their sub-contracted farmers. Collaboration practices were measured as an average score aggregated across three dimensions of collaboration. The descriptive statistics are reported in Appendix A.

The farms' structural characteristics include farm size, location, machinery, the family/hired labour ratio and the farm tenure system. The farmer characteristics include age, education, duration of their relation with the company as subcontractors, association membership, their family income dependence on agriculture and their income dependence on cotton cultivation.

As shown in table 3, the farms are located in four governorates in Egypt; $44 \%$ of the farms are in El-Fayoum, 31\% are in El-Beheera, and 13\% are in El-Dakahelya and El-kalyoubya each. Mixed ownership of the machinery (rented-owned) exists in $56 \%$ of the farms surveyed. $38 \%$ of the farms own their machinery and only one farm rents all the farming machinery needed for cultivation. Concerning farm labour, no farms use family labour exclusively. Mixed labour (family and hired) constitutes $63 \%$ of the farms' labour force, whereas hired labour constitutes only $37 \%$ of the farms' labour force. With regard to land tenure, the majority of the farms are owned (over $80 \%$ of the total number of farms), whereas less than $20 \%$ are mixed ownership (owned-rented).

The largest categories of holders are mainly the age groups of 25 to 45 years old and 46 to 65 years old, both representing $44 \%$ of all the farmers. Education depends on the type of ownership. Almost all the farmers are educated, with the exception being just two farmers. Less than $20 \%$ of the subcontracted farm holders are illiterate. All the farmers are members of the Farmers Development Association (FDA), which receives and manages the Fair-trade Premium. All the farmers have been contracting with the company for a long time, the period ranging from $<10$ years to $>15$. Approximately $70 \%$ of the farmers' families' incomes are highly dependent on agriculture $(>70 \%)$. The rest of the farmers consider their families as having a medium dependency (from 30 to $70 \%$ ) on agriculture. Finally, $75 \%$ of the farmers considered their families' income as having a medium dependency (dependency ratio ranging from 30 to $70 \%$ ) on cotton.

Table 3. Farms and farmers structural characteristics

\begin{tabular}{|c|c|c|}
\hline & $\mathbf{N}^{\circ}$ & $\%$ \\
\hline \multicolumn{3}{|l|}{ Farmers'age } \\
\hline$<25$ yrs & 1 & $6 \%$ \\
\hline $25-45 \mathrm{yrs}$ & 7 & $44 \%$ \\
\hline $46-65 \mathrm{yrs}$ & 7 & $44 \%$ \\
\hline$>65 \mathrm{yrs}$ & 1 & $6 \%$ \\
\hline \multicolumn{3}{|l|}{ Farmers' Education } \\
\hline Illiterates & 2 & $12.5 \%$ \\
\hline Educated & 14 & $87.5 \%$ \\
\hline \multicolumn{3}{|l|}{ Farm sizes $($ ha) } \\
\hline From $<0.42$ to 2.10 (Small) & - & - \\
\hline From $>2.1$ to 8.4 (Medium) & 2 & $13 \%$ \\
\hline From $>8.4$ and over (Large) & 14 & $88 \%$ \\
\hline \multicolumn{3}{|l|}{ Farm location } \\
\hline El-Behera & 5 & $31 \%$ \\
\hline El-Fayoum & 7 & $44 \%$ \\
\hline El-Dakahleya & 2 & $13 \%$ \\
\hline El-kalyobya & 2 & $13 \%$ \\
\hline
\end{tabular}




\begin{tabular}{|c|c|c|}
\hline \multicolumn{3}{|l|}{ Land tenure } \\
\hline Owned & 13 & $81 \%$ \\
\hline Rented & - & - \\
\hline Mixed (owned \&rented) & 3 & $19 \%$ \\
\hline \multicolumn{3}{|l|}{ Farm labour } \\
\hline Family (only) & - & - \\
\hline Hired (only) & 6 & $38 \%$ \\
\hline Family \& hired & 10 & $63 \%$ \\
\hline \multicolumn{3}{|l|}{ Farm machinery } \\
\hline Owned & 6 & $38 \%$ \\
\hline Rented & 1 & $6 \%$ \\
\hline Mixed (owned \& rented) & 9 & $56 \%$ \\
\hline \multicolumn{3}{|c|}{ Duration of sub-contract relation with NaturTex } \\
\hline$<10$ & 8 & $50 \%$ \\
\hline $10-15$ & 5 & $31 \%$ \\
\hline$>15$ & 3 & $19 \%$ \\
\hline \multicolumn{3}{|c|}{ Farmers' association membership } \\
\hline Yes & 16 & $100 \%$ \\
\hline No & - & - \\
\hline \multicolumn{3}{|c|}{ Family's income dependency on agriculture } \\
\hline Low $<30 \%$ & - & - \\
\hline Medium 30-70 \% & 5 & $31 \%$ \\
\hline High $>70 \%$ & 11 & $69 \%$ \\
\hline \multicolumn{3}{|c|}{ Family income dependency on cotton } \\
\hline Low $<30 \%$ & 2 & $13 \%$ \\
\hline Medium $30-70 \%$ & 12 & $75 \%$ \\
\hline High $>70 \%$ & 2 & $13 \%$ \\
\hline
\end{tabular}

\subsection{Factor analysis}

From the exploratory factor analysis, applied to each dimension, six distinct factors were extracted across the three main dimensions of collaboration: information sharing, decision synchronization, and incentive alignment. Two factors were extracted for each collaboration dimension (table 4). The collaboration practices between the leading company (NaturTex) and its contracted farmers were assessed across the three main dimensions of collaboration with regard to these six extracted factors and the correlated items.

Table 4. Factors extracted from the factor analysis.

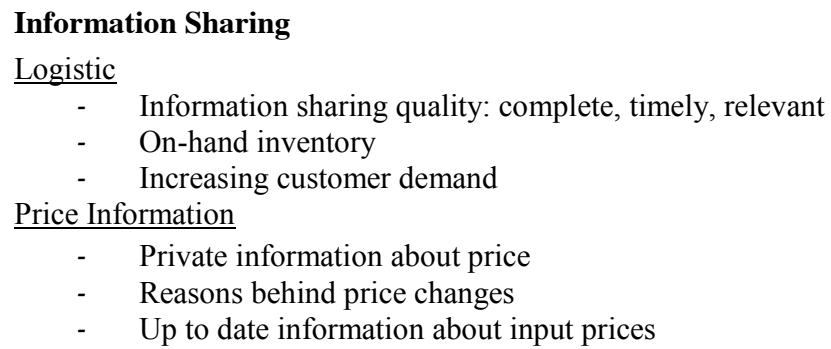

Decision Synchronization

Exception management

- $\quad$ Finding solution on order exceptions

- Jointly setting contract clauses

General management

- $\quad$ Extent of synchronizing decisions between the company \& farmers

- Allowance to give suggestions to change contract 


\section{Incentive Alignment}

Risk sharing

- $\quad$ Subsidize in case cotton price went down

- $\quad$ Financially aid in case any decline of production occurs

Technical support

- $\quad$ Training programs

- Technical assistance

First, as shown in table 5, regarding the dimension of information sharing, the on-hand inventory and increasing customer demand items, together with the information sharing quality items were loaded under the factor named "Logistics". The items related to private information about price, reasons behind price changes, and up-to-date information about input prices were loaded separately from the "Logistics" factor under the factor named "Price Information".

Excluded items include information about fair trade and organic prices, arising issues during cotton cultivation, and farm record/internal inspection (table 8). These items were excluded from the collaboration index because they did not show any level of variability. They could not be processed in the factor analysis because the items need a minimum variance.

The extraction of two factors, "Logistics" and "Price Information", provides Sekem more detailed measurement sub-scales identifying the two main components of information sharing.

Table 5. Factor loadings. Information sharing dimension.

\begin{tabular}{llccc}
\hline Items & & Logistic & Price Information & Communalities \\
\hline IS_12 & Information Sharing quality: Complete & .821 & & .758 \\
IS_13 & Information Sharing quality: Timely & .762 & .610 \\
IS_6 & On-hand inventory & .703 & .659 \\
IS_11 & Information Sharing quality: Relevant & .556 & & .323 \\
IS_5 & Increasing customer demand & .325 & & .107 \\
\hline IS_4 & Private information about price & & .876 & .791 \\
IS_3 & Reasons behind price changes & & .811 & .769 \\
IS_8 & Up to date Information about input price & & .532 & .446 \\
\hline \% of variance & 32.742 & 23.048 & \\
Cumulative \% of variance & 32.742 & 55.791 & \\
\hline
\end{tabular}

Extraction Method: Principal Component Analysis.

Second, as shown in table 6, regarding the decision synchronization dimension, two factors were extracted. The items related to finding solution on order exceptions and new requirement to be added in the contract clauses were grouped and loaded under the factor named "Exception Management". The items related to the extent of synchronizing decisions between the farmers and the company and allowance to give suggestions to contract were grouped and loaded under the factor named "General Management". In addition, in this case, some items showing a variance equal to zero were excluded from representing the decision synchronization dimension in the collaboration index development. These items involve contract clauses, pricing policy, payment policy, optimal order quantity, and delivery agreements (table 8). 
Table 6. Factor loadings. Decision Synchronization dimension

\begin{tabular}{|c|c|c|c|c|}
\hline \multicolumn{2}{|l|}{ Items } & \multirow{2}{*}{$\begin{array}{c}\begin{array}{c}\text { Exception } \\
\text { Management }\end{array} \\
.814\end{array}$} & \multirow[t]{2}{*}{$\begin{array}{c}\text { General } \\
\text { Management }\end{array}$} & \multirow{2}{*}{$\begin{array}{c}\text { Communalities } \\
.681\end{array}$} \\
\hline DS_7 & Finding solutions on order exceptions & & & \\
\hline $\begin{array}{l}\text { DS_3 } \\
\text { clauses }\end{array}$ & New requirements to be added to the contract & .775 & & .801 \\
\hline DS_10 & $\begin{array}{l}\text { Extent of synchronizing decisions between the } \\
\text { farmers and the company }\end{array}$ & & .826 & .698 \\
\hline DS_2 & Allowance to give suggestions to contract & & .768 & .809 \\
\hline \multicolumn{2}{|c|}{$\%$ of variance } & 49.589 & 25.152 & \\
\hline \multicolumn{2}{|c|}{ Cumulative $\%$ of variance } & 49.589 & 74.741 & \\
\hline
\end{tabular}

Extraction Method: Principal Component Analysis.

Third, as shown in table 7, regarding the dimension of incentive alignment, the items subsidize in case the cotton market price went down and financially aid in case any decline of production occurs because of any environmental/agronomic reasons were grouped and loaded under the factor name "Sharing Risks". The items related to the training programs and technical assistance were grouped and loaded under the factor named "Technical Support". Some items were also excluded from the factor analysis when measuring the incentive alignment dimension due to their variance being equal to zero. These items include sharing cost of production items (certification, inputs, hiring part time labour and transportation) (table 8).

Table 7. Factor loadings. Incentive Alignment dimension

\begin{tabular}{llccc}
\hline Items & & Risk Sharing & Technical support & Communalities \\
\hline IA_1 & $\begin{array}{l}\text { Subsidize if cotton price went down } \\
\text { IA_2 }\end{array}$ & $\begin{array}{l}\text { Financially aid if any decline of } \\
\text { production occurs }\end{array}$ & .913 & .857 \\
\hline IA_8 & $\begin{array}{l}\text { Training programs } \\
\text { IA_9 }\end{array}$ & Technical assistance & & \\
\hline \% of variance & & .851 & .726 \\
Cumulative \% of variance & 48.039 & .634 & .855 \\
\hline
\end{tabular}

Extraction Method: Principal Component Analysis.

It is worth noting that the exclusion of some items originally included in the three dimensions of collaboration does not mean that they are not relevant to the context of collaboration in organic and fair trade cotton. Instead, these items (see table 8, Appendix A), due to their low statistical variance, cannot be included in an index developed for the Egyptian context. This does not mean they were not considered when interpreting the results. They show constant very low (1) or very high (5) Likert scale scores when referring to important aspects of the relationship between farmers and buyers in an organic and fair trade context. 
Table 8. Excluded items from the collaboration index development

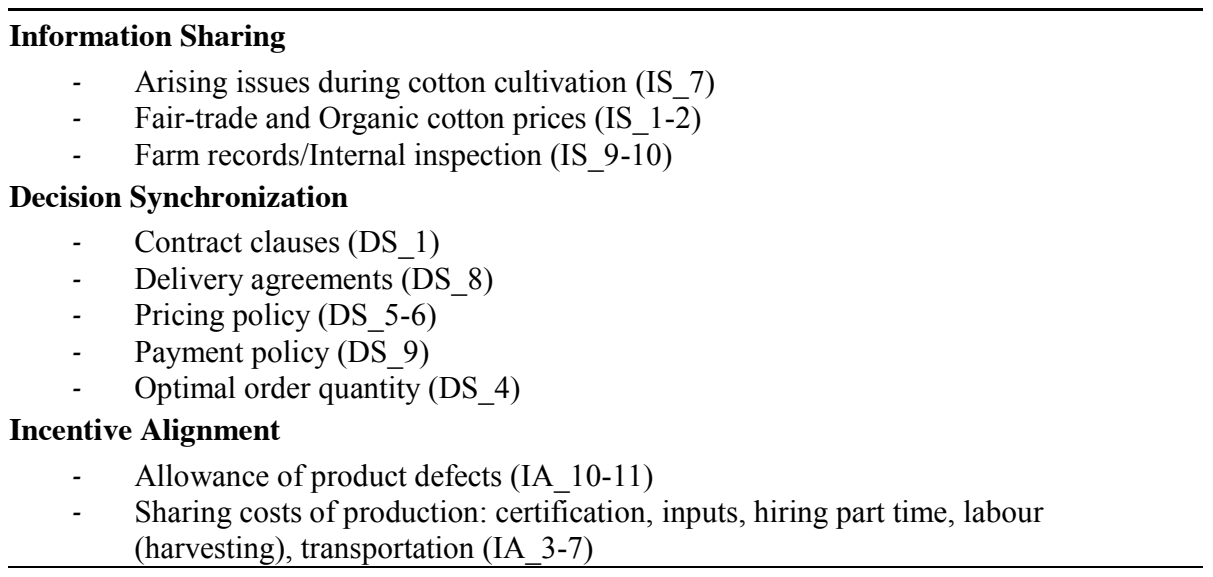

The obtained factor loadings are greater than 0.50 (tables 5, 6, and 7), showing strong correlations of each item on its associated factor. Moreover, the total variance accounted for by all factor under three dimensions are greater than 50\%: information sharing, 55\% and 79\%; decision synchronization, 74\% and 74\%; and incentive alignment, 78\% and 78\%. These results show high inter-correlation among the items and validate the sub-scales obtained thorough the performed EFA. To further validate the robustness of the defined collaboration index instrument, a reliability test was carried out using Cronbach's alpha. Table 9 shows the reliability of each sub-scale (extracted factors).

Table 9. Reliability test

\begin{tabular}{lc}
\hline Factors & Cronbach's alpha (0>.70) \\
\hline Information sharing & .711 \\
Logistics (5 items) & .657 \\
Price information (3 items) & \\
\hline Decision synchronization & .533 \\
Exception management (2 items) & .549 \\
General management (2 items) & \\
\hline Incentive alignment & .794 \\
Risk sharing (2 items) & .402 \\
Technical support (2 items) & \\
\hline
\end{tabular}

\subsection{Collaboration index measurement}

The level of collaboration between NaturTex and the contracted farmers has been calculated as an average of the scores obtained by the three dimensions of collaboration. As shown in table 10, the average scores of information sharing, decision synchronization, and incentive alignment are 3.35, 2.93 , and 2.88, respectively.

The average score of the collaboration index is 3.12 , very similar to each of its dimension's scores given their very low variability.

Within these three dimensions, the items selected and the factors emerging from the factor analysis provide different levels of contribution to the collaboration index (Figures 1 and 2). The main contribution to information sharing is attributed to the factor "Logistic", with a weighted average score of 4.02 resulting mainly from the items related to the quality of the shared information. In contrast, the items related to the factor "Price Information" show lower scores. The factor "Exception Management" contributes more to the decision synchronization dimension score than the factor "General Management", with scores of 3.20 and 2.65, respectively. 
Finally, the main contribution to the dimension incentive alignment is provided by the factor "Technical Support", with an average score of 4.55. A much lower contribution is provided by the items related to the factor "Risk sharing", showing an average score of 1.2.

Table 10. Items and dimensions average scores

\begin{tabular}{|c|c|c|}
\hline & Items & Dimensions \\
\hline Information Sharing & & 3.35 \\
\hline Logistic & & 4.02 \\
\hline Quality: Complete & 3.3 & \\
\hline Quality: Timely & 4.9 & \\
\hline Quality: Relevant & 4.2 & \\
\hline On-hand Inventory & 3.7 & \\
\hline Increasing customer demand & 4 & \\
\hline Price Information & & 2.23 \\
\hline Price & 1.6 & \\
\hline Price changes & 2.8 & \\
\hline Input prices & 2.3 & \\
\hline Decisions Synchronization & & 2.93 \\
\hline Exception Management & & 3.20 \\
\hline Solutions on order exception & 3 & \\
\hline New requirements to the contract clauses & 3.4 & \\
\hline General Management & & 2.65 \\
\hline Extent of synchronizing decisions & 3.1 & \\
\hline Allowance to give suggestions to contract & 2.2 & \\
\hline Incentive Alignment & & 2.88 \\
\hline Risk Sharing & & 1.20 \\
\hline Subsidize if cotton price went down & 1.1 & \\
\hline Financially aid if any decline of production occurs & 1.3 & \\
\hline Technical Support & & 4.55 \\
\hline Training programs & 4.6 & \\
\hline Technical assistance & 4.5 & \\
\hline
\end{tabular}


Figure 1. Items of Supply Chain Collaboration: averages scores

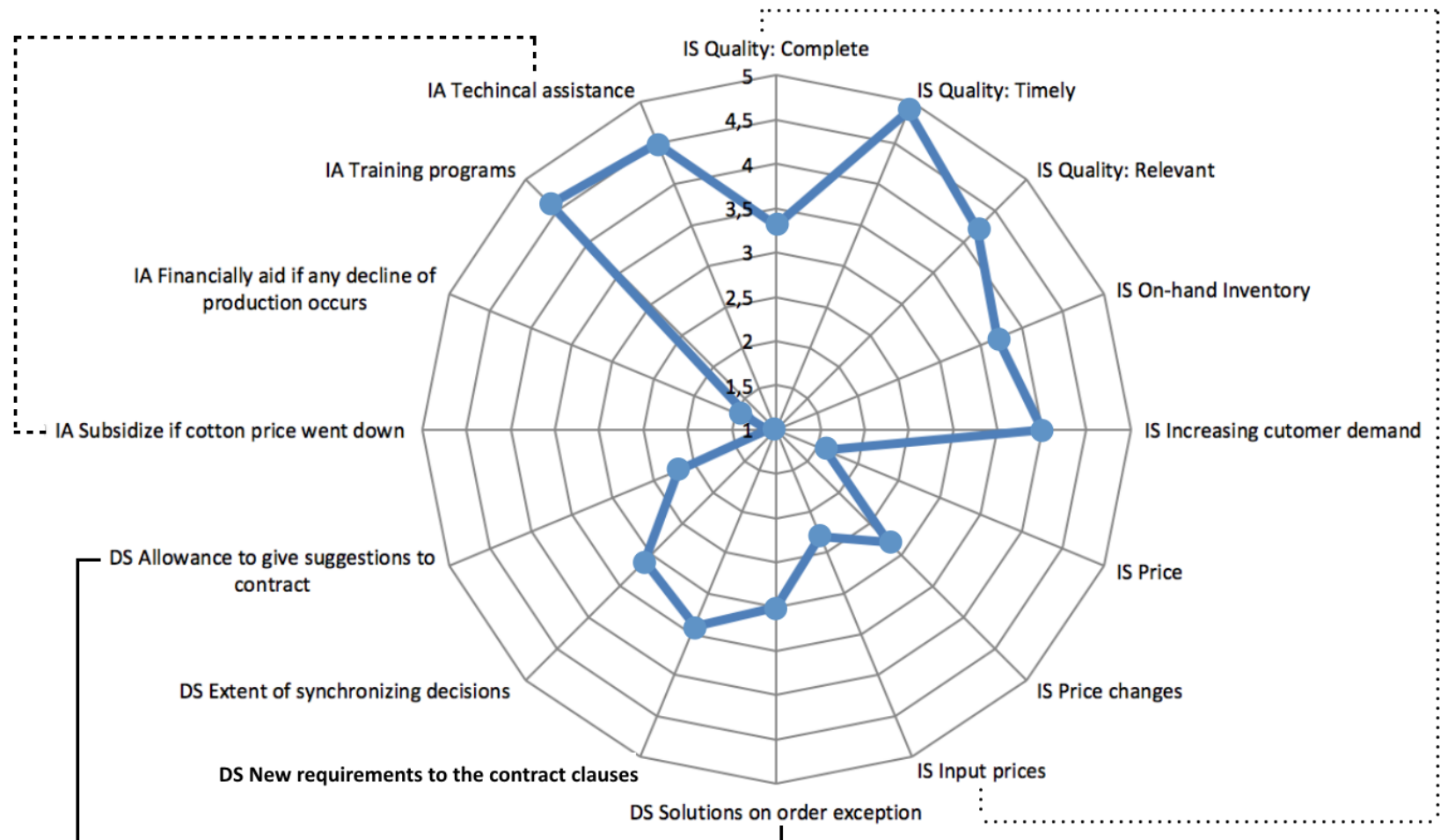

Figure 2. Dimensions and factors of Supply Chain Collaboration: averages scores

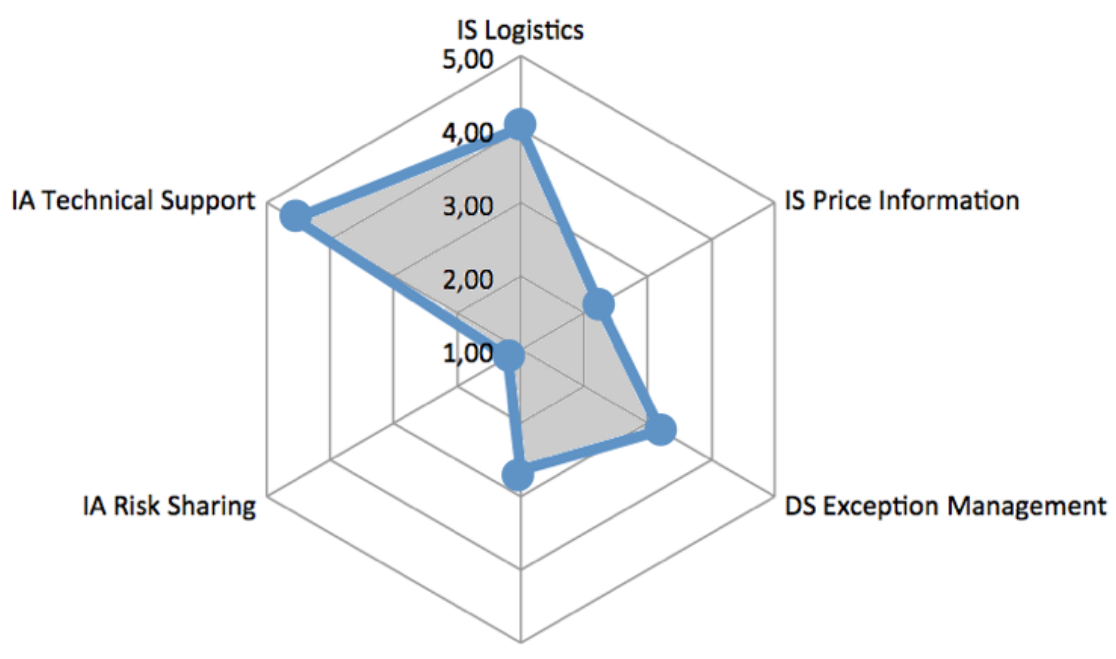

DS General Management 


\section{Discussion and Conclusions}

\subsection{Discussion}

The analysis of the structural characteristics of the sample show that the organic cotton farmers involved in a contractual relationship with NaturTex are relatively larger, younger and better educated than the average Egyptian farmers. Their transactions with other chain agents are broad in scope and relatively complex; they involve selling organic certified cotton and acquiring labour, land and physical capital.

The study shows that the items involved in the proposed collaboration index identify homogeneous and relevant factors affecting the farmers-processor relationship within an organic and fair trade food and fibre chain, confirming the literature findings. The items defining the index can be applied to other contexts. The wide range of indications to chain stakeholders covers different areas of chain relations. All these aspects indicate that the study provided an effective and efficient monitoring tool supporting the definition of a chain collaboration strategy.

In particular, the results showed that the level of collaboration between NaturTex and the farmers is close to 3 out of 5 , showing an average degree of collaboration. The same applies to the different collaboration dimensions, which show very low variability in their contribution to the aggregated score. Improvements are needed in each dimension to increase the collaborative performance within the organic and fair trade cotton chain in Egypt. This can be done examining the contribution of different factors and items to the collaborative performance (the Collaboration Index score).

The Information Sharing dimension shows that the items related to the factor "Logistics" positively influence the collaboration between farmers and the leading company; these items show average scores ranging from 3.3 to 4.9 (see Appendix A). The items related to the factor "Price Information" show relatively lower scores, suggesting that the leading company should more openly share information on prices with their suppliers, particularly as far as Organic cotton premium information and information on input prices are concerned.

The dimension Decision Synchronization shows two main factors contributing to the dimension total score: "Exception Management" and "General Management". The factor "Exception Management" is also related to the logistics management and includes a highly correlated item, finding solutions on order exceptions, which exhibits an average score. The other item, jointly modifying contract clauses, shows an above the average score. The latter is more strictly connected to the definition of the contractual relationship and the most related to logistics. The item finding solutions on order exceptions proves to be a little more problematic to manage than the factor "Logistics"; the joint definition of contractual relationships is more successfully managed by the leading company. Moreover, farmers require decisions concerning order exceptions to be prioritized when defining the new requirements that need to be added to the contract.

The items in the factor "General Management" include give suggestions to change contract, whose low score partially contradicts the indications from the item joint definition of contractual relationships. The second item of the General Management factor, extent of synchronizing decisions between farmers and company, confirms the low scores of the first item. A possible explanation is that when jointly defining the contractual relationships the role of farmers in giving suggestions to change contract is less relevant than the leading company, due to different technical and managerial skills and, possibly, different levels of contractual power.

This indicates the capacity of the leading company to organize its relations with farmers more efficiently from the logistics side but less effectively in involving the farmers when the content of the decisions is at stake.

Two factors are loaded under the last dimension of collaboration analysed, Incentive Alignment. They are "Risk Sharing" and "Technical Support". The items included in the "Risk Sharing" factor, subsidies to farmers in case the cotton price went down and sharing risk in case any decline of production occurs, show very low scores, indicating that the company should increase its participation in the risks related to cotton production. 
The items included in the factor "Technical Support", training programs and technical assistance, show higher than average scores, indicating a strong orientation of the leading company towards supporting farmers from a technical point of view.

Summarizing these considerations, NaturTex, as expected, is more conservative as far as two very sensitive issues are concerned: sharing information on prices and sharing risk. In contrast, technical assistance, logistics and training seem to be very well managed, in line with the above-mentioned analysis of Perez-Aleman and Sandilands (2008) on the 'active assistance approach'.

In particular, from the discussion with the respondent farmers, which is integrated with the questionnaire data collection, it turned out that the farmers see technical support as an important incentive when collaborating with the company because it provides them knowledge and experience with regard to the agronomic aspects. These findings are in line with other works in which improved technical skills represent one of the main asset for farmers under organic certification systems (Nelson and Galvez, 2000; Ronchi, 2002; Zanasi et al., 2010).

Therefore, the leading company should increase the farmers' involvement in the chain management, as far as decisions alignment, risk sharing and price information are concerned, mostly considering the farmers' increased capability and awareness of their role in the chain, due to effective technical and economic assistance.

Regarding the items excluded from the factor analysis, their scores confirm the study findings: the excluded items related to price setting, the price premium and the contribution to the production costs show very low scores ( 1 out of 5) (see table 8 , Appendix A). In contrast, higher values are related to those items involving logistics and technical assistance, confirming the indications provided by the items loaded in the factor analysis.

Even if they are not statistically significant, these last results confirm widespread opinions that should be further investigated by the NaturTex management. The contribution of the excluded items to the collaboration index assessment can be tested when measuring the level of collaboration in other organic and fair trade cotton chains.

The study's practical implications for the lead company involve the availability of a more detailed monitoring and decision support tool able to improve the level of collaboration with contracted farmers. The items describing the level of collaboration also provide useful indications to collaborative strategies for supporting farmers in achieving a higher level of technical and managerial skills and reducing their vulnerability to price volatility through a more favourable and stable price setting within long/medium-term contracts. This in turn will influence farmers' compliance with fair trade and organic agriculture standards and create better chain sustainability performance. In this way, the collaboration index supports effective sustainability and collaborative strategies. As for the efficiency of the strategies, the collaboration index provides stakeholders with a focused and clearly defined set of relevant improvement needs, reducing the cost and improving the benefits of implementing strategies.

\subsection{Conclusions}

A collaboration index adapted to the organic and fair trade cotton chain in Egypt, and different factors influencing collaborative performance have been defined. This study provides useful indications on how to implement more effective and efficient collaborative chain strategies. Collaboration is particularly relevant because it not only represents a chance to improve the chain's competitiveness and farmers' well being but is also one of the principles of organic and fair trade funding, which translate into certification rules of transparency and, most pertinently for fair trade, joint management procedures. The present study contributes to the debate on innovative and sustainable models of production and consumptions by introducing a collaboration index for assessing business performances and success in new ways. It also contributes to support sustainable supply chain management in the food and fibre sector.

The scientific value provided by the study consists of the development of a conceptual framework, a reliability assessment and the validation of a tool for measuring a collaboration index and 
assessing the level of collaboration within a food and fibre chain. In particular, the results of this empirical analysis show that the adaptation of the collaboration index approach to a different context works. Valid and reliable measurement scales have in fact been developed; this means that the items included in the questionnaire can also be applied to other organic and fair trade chains. Furthermore, the factor analysis showed that the items proposed proved to be consistent with theoretical assumptions and can be adopted in the assessment of the collaboration index.

Some issues emerged from this study that need to be discussed, improved upon or further investigated. The first is related to the low values of Cronbach's alpha in some scales. This could be considered a measure of low reliability. However, Alpha is dependent not only on the magnitude of the correlations among items but also on the number of items involved in the measurement scales (Streiner et al., 2014). Thus, to increase alpha, more related items testing the same concept should be added to the scale. Considering the exploratory nature of the present study and the performed factor analysis (EFA), a possible reduction in the original items involved in each factor was expected, thereby negatively affecting the values of alpha. In addition, these low values do not influence the meaning or the importance of the factors extracted (Tavakol and Dennick, 2011).

The sensitivity of the factor analysis toward the minimum variance needed for each item in the instrument led to the exclusion of various items from the index. Such items simply did not show any variance because they are associated with specific issues that appear to be constant in the daily relations between the company and contracted farmers. Although such items could not be directly included in the collaboration index, they were duly considered in the description of the context of the research and in the interpretation of the results.

The study provides several directions for further research, particularly in terms of increasing the number of variables and the sample size. A larger sample of farmers is needed not only to increase the statistical significance of the results but also to allow for the inclusion of more variables in the model representing the three main dimensions of collaboration. Future research should also investigate, create and validate the measurement scales in other contexts, considering more items and acceptable values of Cronbach's alpha. 


\section{APPENDIX A}

\section{Information Sharing (excluded questions in bold)}

\begin{tabular}{l|l|c|c}
\hline Code & \multicolumn{1}{|c|}{ Items question } & Mean & SD \\
\hline IS_1 & Company-farmers sharing information regarding fair-trade cotton prices & $\mathbf{4 . 7}$ & $\mathbf{0 . 7 0}$ \\
IS_2 & Company-farmers sharing information organic cotton premium & $\mathbf{1}$ & $\mathbf{0}$ \\
IS_3 & Changes in prices (yes/no); company-farmers sharing information about the & 2.8 & 1.51 \\
& reasons behind such changes & 1.6 & 0.89 \\
IS_4 & Company-farmers sharing information about private information & 4 & 0.85 \\
IS_5 & Company-farmers sharing information concerning increasing customer demand & 3.7 & 1.61 \\
IS_6 & Farmers- company sharing information about the on hand inventory & $\mathbf{5}$ & $\mathbf{0}$ \\
IS_7 & Farmers-company sharing information about arising issues during cotton & & \\
& cultivation & 2.3 & 1.44 \\
IS_8 & Company-farmers sharing information about the updates of input prices & $\mathbf{4 . 9}$ & $\mathbf{0 . 2 5}$ \\
IS_9 & Farmers-company sharing farm records & $\mathbf{5}$ & $\mathbf{0}$ \\
IS_10 & Company-farmers sharing information after internal inspection & 3.2 & 0.68 \\
IS_11 & Information sharing with the company-farmers is relevant & 0.85 \\
IS_12 & Information sharing with the company-farmers is complete & 4.9 & 0.25 \\
IS_13 & Information sharing with the company-farmers is timely & & \\
\hline
\end{tabular}

\section{Decision synchronization (excluded questions in bold)}

\begin{tabular}{l|l|c|c}
\hline Code & \multicolumn{1}{|c|}{ Items question } & Mean & SD \\
\hline DS_1 & Company-farmers jointly setting contract clauses & $\mathbf{4 . 9}$ & $\mathbf{0 . 2 5}$ \\
DS_2 & Farmers ability to give suggestions to be added to contract & 2.2 & 0.77 \\
DS_3 & Company-farmers Mutual discussion of any new requirement & 3.4 & 1.63 \\
DS_4 & Company-farmers decision over the optimal order quantity & $\mathbf{5}$ & $\mathbf{0}$ \\
DS_5 & Company -farmers jointly setting fair-trade prices & $\mathbf{1}$ & $\mathbf{0}$ \\
DS_6 & Company -farmers jointly setting organic premium & $\mathbf{1}$ & $\mathbf{0}$ \\
DS_7 & Company-farmers jointly finding solutions on order exception & 3.0 & 1.06 \\
DS_8 & Company- farmers jointly making the delivery agreements & $\mathbf{5}$ & $\mathbf{0}$ \\
DS_9 & Company-farmers jointly deciding about payment (schedule/ways) & $\mathbf{1}$ & $\mathbf{0}$ \\
DS_10 & The extent company-farmers are synchronizing decisions & 3.1 & 0.34 \\
\hline
\end{tabular}

\section{Incentive alignment (excluded questions in bold)}

\begin{tabular}{l|l|c|c}
\hline Code & \multicolumn{1}{|c|}{ Items question } & Mean & SD \\
\hline IA_1 & Company subsidizes to farmers in case the cotton prices went down & 1.1 & 0.34 \\
IA_2 & Company sharing risk in case any decline of production occurs & 1.3 & 0.70 \\
IA_3 & Company shares the cost of organic and fair-trade certificate & $\mathbf{1}$ & $\mathbf{0}$ \\
IA_4 & Company shares the cost of cotton transportation & $\mathbf{5}$ & $\mathbf{0}$ \\
IA_5 & Company shares the cost of production (input cost/supply) & $\mathbf{1}$ & $\mathbf{0}$ \\
IA_6 & Company shares the cost of production (supplying further inputs) during & $\mathbf{1}$ & $\mathbf{0}$ \\
& if needed during cultivation & $\mathbf{1}$ & $\mathbf{0}$ \\
IA_7 & Company shares the cost of hiring part time labour & 4.6 & 0.62 \\
IA_8 & Company-farmers training programs & 4.5 & 0.63 \\
IA_9 & Company-farmers technical assistance during cultivation & & \\
\hline
\end{tabular}




\begin{tabular}{l|l|c|c}
\hline IA_10 & Company response to farmers technical assistance calls & 4.9 & 0.25 \\
IA_11 & Company support to farmers by supplying inputs & $\mathbf{0}$ & $\mathbf{1}$ \\
\hline
\end{tabular}

\section{Appendix B - Questionnaire}

\section{Information Sharing}

IS_1 To what extent is the company sharing information with you regarding fair-trade cotton prices?

IS_2 To what extent is the company sharing information with you regarding the organic cotton premium?

IS_3 Did you experience any changes in prices in recent years? (yes/no) If yes has the company shared with you information about the reasons behind such changes?

IS_4 Does the company share with you any private information (like for instance for how much they are buying cotton lint from other cotton farmers)?

IS 5 Does the company share any information with you about the increasing demand by customers?

IS_6 Are you sharing information with the company regarding your on-hand inventory?

IS_7 Do you share with the company information about the issues that you are facing during cotton cultivation, which might affect the forecasted demand by the company?

IS_8 Does the company share with you updates about the input prices on the local market?

IS 9 Do you share with the company your farm records?

IS_ 10 Does the company share information with you after their internal inspection?

Based on what it has been mentioned so far, do you think that the information that you share with the company is:

IS 11 Relevant

IS 12 Complete

IS_13 Timely

\section{Decision Synchronization}

DS 1 Are you and the company jointly setting the clauses attached to the contract?

DS_2 Are you allowed to give any suggestions to change the contract or to add/remove specific clauses from your side?

DS_3 Does the company discuss with you any new requirement to be added to the contract or the clauses?

DS_4 Are you and the company jointly deciding the optimal order (product/cotton) quantity to supply?

DS_5 Are you and the company jointly setting the minimum price for Fair-trade?

DS_6 Are you and the company jointly setting the organic premium price?

DS_7 To which extent you and the company are jointly working on finding out solutions on order exceptions?

DS_8 Are you jointly taking decisions about the delivery agreements?

DS_9 Are you and the company jointly deciding about payment (schedule/ways)?

DS_10 Based on what have been mentioned so far, to which extent you and the company are jointly synchronizing decisions

\section{Incentive Alignment}

IA_1 Does the company share risks by subsidizing you if cotton price goes down?

IA_2 Does the company share risks with you whether any decline in production occurs because of environmental issues or agriculture problems?

IA_3 Do they share with you the cost of organic and fair-trade certification?

IA_4 Do they share with you the cost of production by paying the transportation of the cotton lint after being harvested?

IA 5 Do they share the cost of production by paying/supplying the agricultural inputs needed?

IA_6 Do they share the cost of buying any further inputs if needed during the cultivation season? 
IA_7 Do they share with you the expenses of hiring part time labour for harvesting if needed?

IA_8 Does the company make any training programs for you?

IA_9 Does the company provide technical assistance to you during the cultivation season?

IA_10 Does the company technically assist you in case you ask for help?

IA_11 During the cultivation if you need any further inputs (like bio-fertilizers or bio-pesticides), do they share the cost of buying them?

\section{References}

Barratt, M., 2004. Understanding the meaning of collaboration in the supply chain. Supply Chain Manag. An Int. J. 9, 30-42. doi:10.1108/13598540410517566

Blok, V., Long, T.B., Gaziulusoy, A.I., Ciliz, N., Lozano, R., Huisingh, D., Csutora, M., Boks, C., 2015. From best practices to bridges for a more sustainable future: Advances and challenges in the transition to global sustainable production and consumption: Introduction to the ERSCP stream of the Special volume. J. Clean. Prod. 108, 19-30. doi:10.1016/j.jclepro.2015.04.119

Bowersox, D.J., Closs, D.J., Stank, T.P., 2003. How to master cross-enterprise collaboration. Supply Chain Manag. Rev. 7, 18-27.

Cao, M., Zhang, Q., 2010. Supply chain collaboration: Impact on collaborative advantage and firm performance. J. Oper. Manag. 29, 163-180. doi:10.1016/j.jom.2010.12.008

Christopher, M., 2005. Logistics and Supply Chain Management, Pan American Health. Prentice Hall. doi:10.1016/j.aorn.2010.11.038

Corbett, C.J., Blackburn, J.D., Wassenhove, L.N. Van, 1999. Partnerships to Improve Supply Chains. Management 40, 71.

Crook, T.R., Giunipero, L., Reus, T.H., Handfield, R., Williams, S.K., 2008. Antecedents and outcomes of supply chain effectiveness: an exploratory investigation. J. Manag. Issues 161177.

de Winter, J.C.F., Dodou, D., Wieringa, P.A., 2009. Exploratory Factor Analysis With Small Sample Sizes. Multivariate Behav. Res. 44, 147-181. doi:10.1080/00273170902794206

DeCoster, J., 1998. Overview of factor analysis. Available at: http://www.stat-help.com/notes.html.

Fadeeva, Z., 2005. Promise of sustainability collaboration — potential fulfilled? J. Clean. Prod. 13, 165-174. doi:http://dx.doi.org/10.1016/S0959-6526(03)00125-2

Fayet, L., Vermeulen, W.J.V., 2014. Supporting Smallholders to Access Sustainable Supply Chains: Lessons from the Indian Cotton Supply Chain. Sustain. Dev. 22, 289-310. doi: $10.1002 / \mathrm{sd} .1540$

Gold, S., Hahn, R., Seuring, S., 2013. Sustainable supply chain management in "Base of the Pyramid" food projects-A path to triple bottom line approaches for multinationals? Int. Bus. Rev. 22, 784-799. doi:10.1016/j.ibusrev.2012.12.006

Govindan, K., n.d. Embedding Sustainability Dynamics in Supply Chain Relationship Management and Governance Structures: Introduction, Review and oppurtunities. J. Clean. Prod. doi:http://dx.doi.org/10.1016/j.jclepro.2015.11.036

Govindan, K., Seuring, S., Zhu, Q., Azevedo, S.G., 2016. Accelerating the transition towards sustainability dynamics into supply chain relationship management and governance structures. J. Clean. Prod. 112, Part, 1813-1823. doi:http://dx.doi.org/10.1016/j.jclepro.2015.11.084

Grekova, K., Calantone, R.J., Bremmers, H.J., Trienekens, J.H., Omta, S.W.F., 2016. How environmental collaboration with suppliers and customers influences firm performance: evidence from Dutch food and beverage processors. J. Clean. Prod. 112, Part, 1861-1871. doi:http://dx.doi.org/10.1016/j.jclepro.2015.03.022 
Grekova, K., Calantone, R.J., Bremmers, H.J., Trienekens, J.H., Omta, S.W.F., 2015. How environmental collaboration with suppliers and customers influences firm performance: evidence from Dutch food and beverage processors. J. Clean. Prod. 112, 1861-1871. doi:10.1016/j.jclepro.2015.03.022

Gunasekaran, A., Patel, C., 2001. Performance measures and metrics in a supply chain environment. Int. J. 21, 71-87.

Hensley, R.L., 1999. A review of operations management studies using scale development techniques. J. Oper. Manag. 17, 343-358. doi:10.1016/S0272-6963(98)00051-5

Henson, R.K., Roberts, J.K., 2006. Use of exploratory factor analysis in published research common errors and some comment on improved practice. Educ. Psychol. Meas. 66, 393-416.

Hinkin, T.R., 1995. A Review of Scale Development Practices in the Study of Organizations. J. Manage. 21, 967-988. doi:10.1177/014920639502100509

Kline, P., 2014. An easy guide to factor analysis. Routledge.

Kottila, M., Rönni, P., 2008. Collaboration and trust in two organic food chains. Br. Food J. 110, 376-394. doi:10.1108/00070700810868915

Kristiansen, P., Taji, A., Reganold, J.P., 2006. Organic agriculture: a global perspective. CSIRO publishing.

Kumar, D., Rahman, Z., 2016. Buyer supplier relationship and supply chain sustainability: empirical study of Indian automobile industry. J. Clean. Prod. 131, 836-848. doi:http://dx.doi.org/10.1016/j.jclepro.2016.04.007

Lamming, R., 1993. Beyond partnership: strategies for innovation and lean supply, Business Series. Prentice Hall.

Lee, C.W., Kwon, I.-W.G., Severance, D., 2007. Relationship between supply chain performance and degree of linkage among supplier, internal integration, and customer. Supply Chain Manag. An Int. J. 12, 444-452. doi:10.1108/13598540710826371

Lozano, R., Carpenter, A., Huisingh, D., 2015. A review of "theories of the firm" and their contributions to Corporate Sustainability. J. Clean. Prod. 106, 430-442. doi:10.1016/j.jclepro.2014.05.007

MacCallum, R.C., Widaman, K.F., Zhang, S., Hong, S., 1999. Sample size in factor analysis. Psychol. Methods 4, 84.

McDonald, R.P., 2014. Factor analysis and related methods. Psychology Press.

Mentzer, J.T., Foggin, J.H., Golicic, S.G., 2000. Supply chain collaboration: enablers, impediments, and benefits. Supply Chain Manag. Rev. 4, 52-58.

Mentzer, J.T., Stank, T.P., Esper, T.L., 2008. Supply chain management and its relationship to logistics, marketing, production, and operations management. J. Bus. Logist. 29, 31-46.

Naspetti, S., Lampkin, N., Nicolas, P., Stolze, M., Zanoli, R., 2011. Organic supply chain collaboration: a case study in eight EU countries. J. Food Prod. Mark. 17, 141-162. doi:10.1080/10454446.2011.548733

Nelson, V., Galvez, M., 2000. Social impact of ethical and conventional cocoa trading on forestdependent people in Ecuador. London Univ. Greenwich.

Pagell, M., Shevchenko, A., 2014. Why research in sustainable supply chain management should have no future. J. Supply Chain Manag. 50, 44-55.

Perez-Aleman, P., Sandilands, M., 2008. Building Value at the Top and the Bottom of the Global Supply Chain: MNC-NGO Partnerships and Sustainability. Calif. Manage. Rev. 51, 24-49.

Poirier, C.C., 1999. Advanced supply chain management: How to build a sustained competitive advantage. Berrett-Koehler Publishers.

Porter, M.E., Kramer, M.R., 2011. Creating Shared Value. Harv. Bus. Rev. 89, 62-77.

Ramanathan, U., Bentley, Y., Pang, G., 2014. The role of collaboration in the UK green supply chains: an exploratory study of the perspectives of suppliers, logistics and retailers. J. Clean. Prod. 70, 231-241. doi:10.1016/j.jclepro.2014.02.026

Ramdas, K., Spekman, R.E., 2000. Chain or shackles: understanding what drives supply-chain 
performance. Interfaces (Providence). 30, 3-21.

Riopelle, K., Gloor, P., Miller, C., Gluesing, J., Petzel, R., Archer, A.-M., Fei, R., 2010. The 1st Collaborative Innovation Networks Conference - COINs2009Collaboration for sustainability in a networked world. Procedia - Soc. Behav. Sci. 2, 6597-6609. doi:http://dx.doi.org/10.1016/j.sbspro.2010.04.070

Ronchi, L., 2002. The impact of Fair Trade on producers and their organizations: A case study with Coocafé in Costa Rica. Policy Res. Unit. Sussex Univ. Sussex.

Rota, C., Reynolds, N., Zanasi, C., 2013. Sustainable Food Supply Chains: The Role of Collaboration and Sustainable Relationships. Int. J. Bus. Soc. Sci. 4, 45-53.

Rummel, R.J., 1988. Applied factor analysis. Northwestern University Press.

Sancha, C., Gimenez, C., Sierra, V., 2016. Achieving a socially responsible supply chain through assessment and collaboration. J. Clean. Prod. 112, Part, 1934-1947. doi:http://dx.doi.org/10.1016/j.jclepro.2015.04.137

Schöggl, J.-P., Fritz, M.M.C., Baumgartner, R.J., 2016. Toward supply chain-wide sustainability assessment: a conceptual framework and an aggregation method to assess supply chain performance. J. Clean. Prod. 131, 822-835. doi:http://dx.doi.org/10.1016/j.jclepro.2016.04.035

Seliger, G., Mohd. Yusof, N., Chin, T.A., Tat, H.H., Sulaiman, Z., 2015. 12th Global Conference on Sustainable Manufacturing - Emerging PotentialsGreen Supply Chain Management, Environmental Collaboration and Sustainability Performance. Procedia CIRP 26, 695-699. doi:http://dx.doi.org/10.1016/j.procir.2014.07.035

Seuring, S., Muller, M., 2008. From a literature review to a conceptual framework for sustainable supply chain management. J. Clean. Prod. 16, 1699-1710. doi:10.1016/j.jclepro.2008.04.020

Sheu, C., Yen, H.R., Chae, B., 2006. Determinants of supplier-retailer collaboration: evidence from an international study. Int. J. Oper. Prod. Manag. 26, 24-49. doi:10.1108/01443570610637003

Silvestre, B.S., 2015. Sustainable supply chain management in emerging economies: Environmental turbulence, institutional voids and sustainability trajectories. Int. J. Prod. Econ. 167, 156-169. doi:10.1016/j.ijpe.2015.05.025

Simatupang, T.M., Sridharan, R., 2005a. Supply chain discontent. Bus. Process Manag. J. 11, 349369. doi:10.1108/14637150510609390

Simatupang, T.M., Sridharan, R., 2005b. The collaboration index: a measure for supply chain collaboration. Int. J. Phys. Distrib. Logist. Manag. 35, 44-62. doi:10.1108/09600030510577421

Simatupang, T.M., Sridharan, R., 2004. Benchmarking supply chain collaboration: An empirical study. Benchmarking An Int. J. 11, 484-503. doi:10.1108/14635770410557717

Simatupang, T.M., Sridharan, R., 2002. The Collaborative Supply Chain. Int. J. Logist. Manag. 13, 15-30. doi:10.1108/09574090210806333

Skjoett-Larsen, T., 2003. Supply chain collaboration. Theoretical perspectives and empirical evidence. Int. J. Phys. Distrib. Logist. Manag. 33, 531-549. doi:10.1108/09600030310492788

Spector, P.E., 1992. Summated rating scale construction: An introduction. Sage.

Spekman, R.E., Carraway, R., 2006. Making the transition to collaborative buyer-seller relationships: An emerging framework. Ind. Mark. Manag. 35, 10-19. doi:10.1016/j.indmarman.2005.07.002

Streiner, D.L., Norman, G.R., Cairney, J., 2014. Health measurement scales: a practical guide to their development and use. Oxford university press.

Tavakol, M., Dennick, R., 2011. Making sense of Cronbach's alpha. Int. J. Med. Educ. 2, 53-55.

Textile Exchange, 2015. Organic cotton market report 2014 1-56.

Touboulic, A., Walker, H., 2015. Love me, love me not: A nuanced view on collaboration in sustainable supply chains. J. Purch. Supply Manag. 21, 178-191. doi:10.1016/j.pursup.2015.05.001

Van Hoof, B., Thiell, M., 2014. Collaboration capacity for sustainable supply chain management: Small and medium-sized enterprises in Mexico. J. Clean. Prod. 67, 239-248. 
doi:10.1016/j.jclepro.2013.12.030

Wagner, B.A., Macbeth, D.K., Boddy, D., 2002. Improving supply chain relations: an empirical case study. Supply Chain Manag. An Int. J. 7, 253-264.

Zanasi, C., Rota, C., Bontempi, S., Panini, G., Setti, M., 2010. Farmers' perceived impact of Fair Trade: the case of Costa Rica. J. Environ. Sci. Eng. 4, 78-84. 
Table 1. Overview of the four methodological steps

\begin{tabular}{ll|l|l}
\hline \multicolumn{1}{c|}{ STEPS } & \multicolumn{1}{c|}{ CONTENT } & \multicolumn{1}{c}{ METHOD } \\
\hline $2.1 \quad$ CONCEPTUALIZATION & $\begin{array}{l}\text { Develop the theoretical } \\
\text { framework (constructs) }\end{array}$ & Literature review \\
\hline \multirow{2}{*}{2.2 SCALE DEVELOPMENT } & $\begin{array}{l}\text { Generate items and define the } \\
\text { questionnaire }\end{array}$ & $\begin{array}{l}\text { Literature review } \\
\text { Researcher' } \\
\text { hypothesis }\end{array}$ \\
\cline { 3 - 4 } & $\begin{array}{l}\text { Assess the content validity of } \\
\text { the items }\end{array}$ & Expert panel \\
\hline \multirow{2}{*}{ DATA COLLECTION } & Collect quantitative data & $\begin{array}{l}\text { Structured } \\
\text { interview }\end{array}$ \\
\hline \multirow{2}{*}{2.4} & SCALE EVALUATION & Assess the construct validity & Factor Analysis \\
\cline { 3 - 4 } & Reduce the items & Cronbach's alpha \\
\cline { 3 - 4 } & Assess the reliability &
\end{tabular}

\section{Table 2. Items statements compiled to define a collaboration measurement instrument}

\section{Information Sharing}

1. Arising issues during cotton cultivation

2. Organic Cotton prices

3. Input prices

4. Prices changes

5. On-hand inventory levels

6. Increasing demand

7. Farm record/Internal Inspection

8. Information quality

Decision Synchronization

9. Joint plan on product assortment

10. Delivery agreements

11. Joint resolution on forecast exceptions

12. Pricing policy

13. Payment policy

14. Optimal order quantity

15. New requirements to be added to the contract

\section{Incentive Alignment}

16. Allowance of product defects

17. Sharing risks by subsidize and financial aids

18. Training programs

19. Technical assistance

20. Sharing costs of production (certification, inputs, transportation) 
Table 3. Farms and farmers characteristics

\begin{tabular}{|c|c|c|}
\hline & $\mathbf{N}^{\circ}$ & $\%$ \\
\hline \multicolumn{3}{|l|}{ Farmers'age } \\
\hline$<25 \mathrm{yrs}$ & 1 & $6 \%$ \\
\hline $25-45 \mathrm{yrs}$ & 7 & $44 \%$ \\
\hline $46-65 \mathrm{yrs}$ & 7 & $44 \%$ \\
\hline$>65 \mathrm{yrs}$ & 1 & $6 \%$ \\
\hline \multicolumn{3}{|l|}{ Farmers' Education } \\
\hline Illiterates & 2 & $12.5 \%$ \\
\hline Educated & 14 & $87.5 \%$ \\
\hline \multicolumn{3}{|l|}{ Farm sizes (ha) } \\
\hline From $<0.42$ to 2.10 (Small) & - & - \\
\hline From $>2.1$ to 8.4 (Medium) & 2 & $13 \%$ \\
\hline From $>8.4$ and over (Large) & 14 & $88 \%$ \\
\hline \multicolumn{3}{|l|}{ Farm location } \\
\hline El-Behera & 5 & $31 \%$ \\
\hline El-Fayoum & 7 & $44 \%$ \\
\hline El-Dakahleya & 2 & $13 \%$ \\
\hline El-kalyobya & 2 & $13 \%$ \\
\hline \multicolumn{3}{|l|}{ Land tenure } \\
\hline Owned & 13 & $81 \%$ \\
\hline Rented & - & - \\
\hline Mixed (owned \&rented) & 3 & $19 \%$ \\
\hline \multicolumn{3}{|l|}{ Farm labour } \\
\hline Family (only) & - & - \\
\hline Hired (only) & 6 & $38 \%$ \\
\hline Family \& hired & 10 & $63 \%$ \\
\hline \multicolumn{3}{|l|}{ Farm machinery } \\
\hline Owned & 6 & $38 \%$ \\
\hline Rented & 1 & $6 \%$ \\
\hline Mixed (owned \& rented) & 9 & $56 \%$ \\
\hline \multicolumn{3}{|c|}{ Duration of sub-contract relation with NaturTex } \\
\hline$<10$ & 8 & $50 \%$ \\
\hline $10-15$ & 5 & $31 \%$ \\
\hline$>15$ & 3 & $19 \%$ \\
\hline \multicolumn{3}{|c|}{ Farmers' association membership } \\
\hline Yes & 16 & $100 \%$ \\
\hline No & - & - \\
\hline \multicolumn{3}{|c|}{ Family's income dependency on agriculture } \\
\hline Low $<30 \%$ & - & - \\
\hline Medium 30-70 \% & 5 & $31 \%$ \\
\hline High $>70 \%$ & 11 & $69 \%$ \\
\hline \multicolumn{3}{|c|}{ Family income dependency on cotton } \\
\hline Low $<30 \%$ & 2 & $13 \%$ \\
\hline Medium 30-70 \% & 12 & $75 \%$ \\
\hline High $>70 \%$ & 2 & $13 \%$ \\
\hline
\end{tabular}


Table 4. Factors extracted from the factor analysis.

\section{Information Sharing}

$\underline{\text { Logistic }}$

- Information sharing quality: complete, timely, relevant

- On-hand inventory

- Increasing customer demand

Price Information

- Private information about price

- Reasons behind price changes

- $\quad$ Up to date information about input prices

\section{Decision Synchronization}

Exception management

- $\quad$ Finding solution on order exceptions

- Jointly setting contract clauses

General management

- Extent of synchronizing decisions between the company \& farmers

- Allowance to give suggestions to change contract

\section{Incentive Alignment}

$\underline{\text { Risk sharing }}$

- Subsidize in case cotton price went down

- $\quad$ Financially aid in case any decline of production occurs

Technical support

- $\quad$ Training programs

- Technical assistance

Table 5. Factor loadings. Information sharing dimension.

\begin{tabular}{llccc}
\hline Items & & Logistic & Price Information & Communalities \\
\hline IS_12 & Information Sharing quality: Complete & .821 & & .758 \\
IS_13 & Information Sharing quality: Timely & .762 & .610 \\
IS_6 & On-hand inventory & .703 & .659 \\
IS_11 & Information Sharing quality: Relevant & .556 & & .323 \\
IS_5 & Increasing customer demand & .325 & .107 \\
\hline IS_4 & Private information about price & & .876 & .791 \\
IS_3 & Reasons behind price changes & & .811 & .769 \\
IS_8 & Up to date Information about input price & & .532 & .446 \\
\hline$\%$ of variance & 32.742 & 23.048 & \\
Cumulative \% of variance & 32.742 & 55.791 & \\
\hline
\end{tabular}

Extraction Method: Principal Component Analysis. 
Table 6. Factor loadings. Decision Synchronization dimension

\begin{tabular}{llccc}
\hline Items & & $\begin{array}{c}\text { Exception } \\
\text { Management }\end{array}$ & $\begin{array}{c}\text { General } \\
\text { Management }\end{array}$ & Communalities \\
\hline $\begin{array}{l}\text { DS_7 } \\
\text { DS_3 } \\
\text { clauses }\end{array}$ & Finding solutions on order exceptions & .814 & & .681 \\
\hline DS_10 & $\begin{array}{l}\text { Extent of synchronizing decisions between the } \\
\text { farmers and the company }\end{array}$ & .775 & .801 \\
DS_2 & Allowance to give suggestions to contract & & .826 & .698 \\
\hline \% of variance & 49.589 & .768 & .809 \\
Cumulative \% of variance & 49.589 & 74.741 & \\
\hline
\end{tabular}

Extraction Method: Principal Component Analysis.

Table 7. Factor loadings. Incentive Alignment dimension

\begin{tabular}{llccc}
\hline Items & & Risk Sharing & Technical support & Communalities \\
\hline IA_1 & Subsidize if cotton price went down & .913 & & .857 \\
IA_2 & $\begin{array}{l}\text { Financially aid if any decline of } \\
\text { production occurs }\end{array}$ & .851 & .726 \\
\hline IA_8 & $\begin{array}{l}\text { Training programs } \\
\text { IA_9 }\end{array} \quad$ Technical assistance & & .900 & .855 \\
\hline \% of variance & & .634 & .714 \\
Cumulative \% of variance & 48.039 & 30.747 & \\
\hline
\end{tabular}

Extraction Method: Principal Component Analysis.

Table 8. Excluded items from the collaboration index development

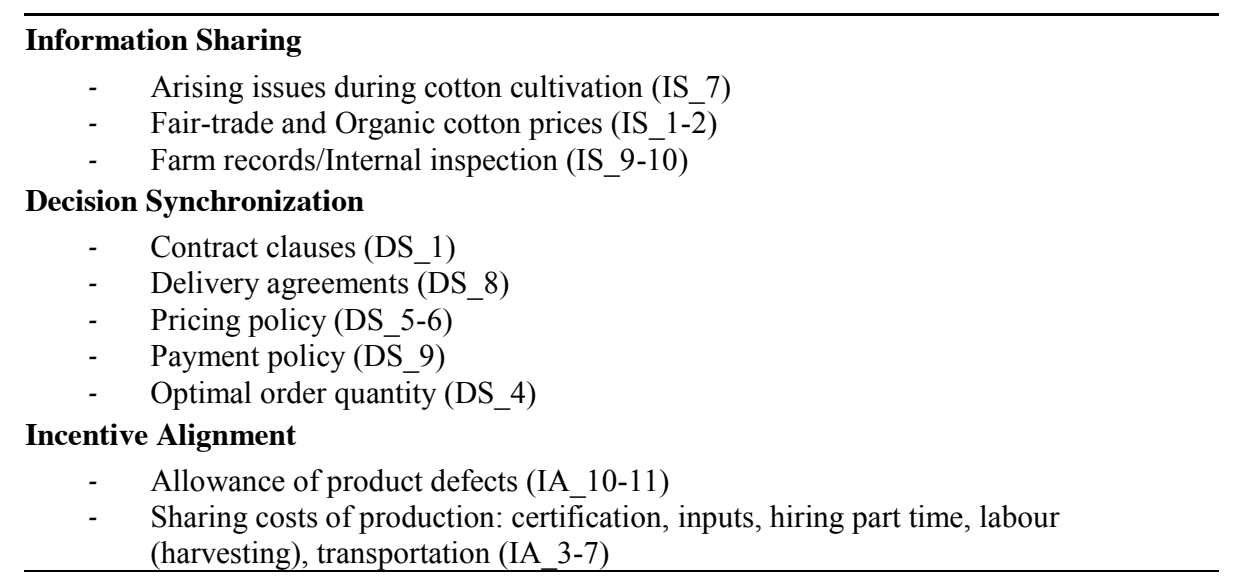


Table 9. Reliability test

\begin{tabular}{lc}
\hline Factors & Cronbach's alpha (0>.70) \\
\hline Information sharing & .711 \\
Logistics (5 items) & .657 \\
Price information (3 items) & .533 \\
\hline Decision synchronization & .549 \\
Exception management (2 items) & \\
General management (2 items) & .794 \\
\hline Incentive alignment & .402 \\
Risk sharing (2 items) & \\
Technical support (2 items) & \\
\hline
\end{tabular}

Table 10. Items and dimensions average scores

\begin{tabular}{|c|c|c|}
\hline & Items & Dimensions \\
\hline Information Sharing & & 3.35 \\
\hline Logistic & & 4.02 \\
\hline Quality: Complete & 3.3 & \\
\hline Quality: Timely & 4.9 & \\
\hline Quality: Relevant & 4,2 & \\
\hline On-hand Inventory & 3.7 & \\
\hline Increasing customer demand & 4 & \\
\hline Price Information & & 2.23 \\
\hline Price & 1.6 & \\
\hline Price changes & 2.8 & \\
\hline Input prices & 2.3 & \\
\hline Decisions Synchronization & & 2.93 \\
\hline Exception Management & & 3.20 \\
\hline Solutions on order exception & 3 & \\
\hline New requirements to the contract clauses & 3.4 & \\
\hline General Management & & 2.65 \\
\hline Extent of synchronizing decisions & 3.1 & \\
\hline Allowance to give suggestions to contract & 2.2 & \\
\hline Incentive Alignment & & 2.88 \\
\hline Risk Sharing & & 1.20 \\
\hline Subsidize if cotton price went down & 1.1 & \\
\hline Financially aid if any decline of production occurs & 1.3 & \\
\hline Technical Support & & 4.55 \\
\hline Training programs & 4.6 & \\
\hline Technical assistance & 4.5 & \\
\hline
\end{tabular}

Collaboration index 


\section{APPENDIX A}

Information Sharing (excluded questions in bold)

\begin{tabular}{l|l|c|c}
\hline Code & \multicolumn{1}{|c|}{ Items question } & Mean & SD \\
\hline IS_1 & Company-farmers sharing information regarding fair-trade cotton prices & $\mathbf{4 . 7}$ & $\mathbf{0 . 7 0}$ \\
IS_2 & Company-farmers sharing information organic cotton premium & $\mathbf{1}$ & $\mathbf{0}$ \\
IS_3 & Changes in prices (yes/no); company-farmers sharing information about the & 2.8 & 1.51 \\
& reasons behind such changes & 1.6 & 0.89 \\
IS_4 & Company-farmers sharing information about private information & 4 & 0.85 \\
IS_5 & Company-farmers sharing information concerning increasing customer demand & 3.7 & 1.61 \\
IS_6 & Farmers- company sharing information about the on hand inventory & $\mathbf{5}$ & $\mathbf{0}$ \\
IS_7 & Farmers-company sharing information about arising issues during cotton & & \\
& cultivation & 2.3 & 1.44 \\
IS_8 & Company-farmers sharing information about the updates of input prices & $\mathbf{4 . 9}$ & $\mathbf{0 . 2 5}$ \\
IS_9 & Farmers-company sharing farm records & 4.2 & $\mathbf{0}$ \\
IS_10 & Company-farmers sharing information after internal inspection & 0.68 \\
IS_11 & Information sharing with the company-farmers is relevant & 3.3 & 0.85 \\
IS_12 & Information sharing with the company-farmers is complete & 4.9 & 0.25 \\
IS_13 & Information sharing with the company-farmers is timely & \\
\hline
\end{tabular}

\section{Decision synchronization (excluded questions in bold)}

\begin{tabular}{l|l|c|c}
\hline Code & \multicolumn{1}{|c|}{ Items question } & Mean & SD \\
\hline DS_1 & Company-farmers jointly setting contract clauses & $\mathbf{4 . 9}$ & $\mathbf{0 . 2 5}$ \\
DS_2 & Farmers ability to give suggestions to be added to contract & 2.2 & 0.77 \\
DS_3 & Company-farmers Mutual discussion of any new requirement & 3.4 & 1.63 \\
DS_4 & Company-farmers decision over the optimal order quantity & $\mathbf{5}$ & $\mathbf{0}$ \\
DS_5 & Company -farmers jointly setting fair-trade prices & $\mathbf{1}$ & $\mathbf{0}$ \\
DS_6 & Company -farmers jointly setting organic premium & $\mathbf{1}$ & $\mathbf{0}$ \\
DS_7 & Company-farmers jointly finding solutions on order exception & 3.0 & 1.06 \\
DS_8 & Company- farmers jointly making the delivery agreements & $\mathbf{5}$ & $\mathbf{0}$ \\
DS_9 & Company-farmers jointly deciding about payment (schedule/ways) & $\mathbf{1}$ & $\mathbf{0}$ \\
DS_10 & The extent company-farmers are synchronizing decisions & 3.1 & 0.34 \\
\hline
\end{tabular}

\section{Incentive alignment (excluded questions in bold)}

\begin{tabular}{l|l|c|c}
\hline Code & \multicolumn{1}{|c}{ Items question } & Mean & SD \\
\hline IA_1 & Company subsidizes to farmers in case the cotton prices went down & 1.1 & 0.34 \\
IA_2 & Company sharing risk in case any decline of production occurs & 1.3 & 0.70 \\
IA_3 & Company shares the cost of organic and fair-trade certificate & $\mathbf{1}$ & $\mathbf{0}$ \\
IA_4 & Company shares the cost of cotton transportation & $\mathbf{5}$ & $\mathbf{0}$ \\
IA_5 & Company shares the cost of production (input cost/supply) & $\mathbf{1}$ & $\mathbf{0}$ \\
IA_6 & Company shares the cost of production (supplying further inputs) during & $\mathbf{1}$ & $\mathbf{0}$ \\
& if needed during cultivation & $\mathbf{1}$ & $\mathbf{0}$ \\
IA_7 & Company shares the cost of hiring part time labour & 4.6 & 0.62 \\
IA_8 & Company-farmers training programs & 4.5 & 0.63 \\
IA_9 & Company-farmers technical assistance during cultivation & 4.9 & 0.25 \\
IA_10 & Company response to farmers technical assistance calls & $\mathbf{1}$ & $\mathbf{0}$ \\
IA_11 & Company support to farmers by supplying inputs & & \\
\hline
\end{tabular}




\section{Appendix B - Questionnaire}

\section{Information Sharing}

IS 1 To what extent is the company sharing information with you regarding fair-trade cotton prices?

IS_2 To what extent is the company sharing information with you regarding the organic cotton premium?

IS_3 Did you experience any changes in prices in recent years? (yes/no) If yes has the company shared with you information about the reasons behind such changes?

IS_4 Does the company share with you any private information (like for instance for how much they are buying cotton lint from other cotton farmers)?

IS_5 Does the company share any information with you about the increasing demand by customers?

IS_6 Are you sharing information with the company regarding your on-hand inventory?

IS_7 Do you share with the company information about the issues that you are facing during cotton cultivation, which might affect the forecasted demand by the company?

IS_8 Does the company share with you updates about the input prices on the local market?

IS 9 Do you share with the company your farm records?

IS_-10 Does the company share information with you after their internal inspection?

Based on what it has been mentioned so far, do you think that the information that you share with the company is:

IS 11 Relevant

IS_12 Complete

IS_13 Timely

\section{Decision Synchronization}

DS_1 Are you and the company jointly setting the clauses attached to the contract?

DS_2 Are you allowed to give any suggestions to change the contract or to add/remove specific clauses from your side?

DS 3 Does the company discuss with you any new requirement to be added to the contract or the clauses?

DS_4 Are you and the company jointly deciding the optimal order (product/cotton) quantity to supply?

DS_5 Are you and the company jointly setting the minimum price for Fair-trade?

DS_6 Are you and the company jointly setting the organic premium price?

DS 7 To which extent you and the company are jointly working on finding out solutions on order exceptions?

DS_ 8 Are you jointly taking decisions about the delivery agreements?

DS_9 Are you and the company jointly deciding about payment (schedule/ways)?

DS_10 Based on what have been mentioned so far, to which extent you and the company are jointly synchronizing decisions

\section{Incentive Alignment}

IA_1 Does the company share risks by subsidizing you if cotton price goes down?

IA_2 Does the company share risks with you whether any decline in production occurs because of environmental issues or agriculture problems?

IA_3 Do they share with you the cost of organic and fair-trade certification?

IA_4 Do they share with you the cost of production by paying the transportation of the cotton lint after being harvested?

IA_5 Do they share the cost of production by paying/supplying the agricultural inputs needed?

IA_6 Do they share the cost of buying any further inputs if needed during the cultivation season?

IA_7 Do they share with you the expenses of hiring part time labour for harvesting if needed?

IA_8 Does the company make any training programs for you?

IA_9 Does the company provide technical assistance to you during the cultivation season?

IA_10 Does the company technically assist you in case you ask for help?

IA_11 During the cultivation if you need any further inputs (like bio-fertilizers or bio-pesticides), do they share the cost of buying them? 
Figure 1. Items of Supply Chain Collaboration: averages scores

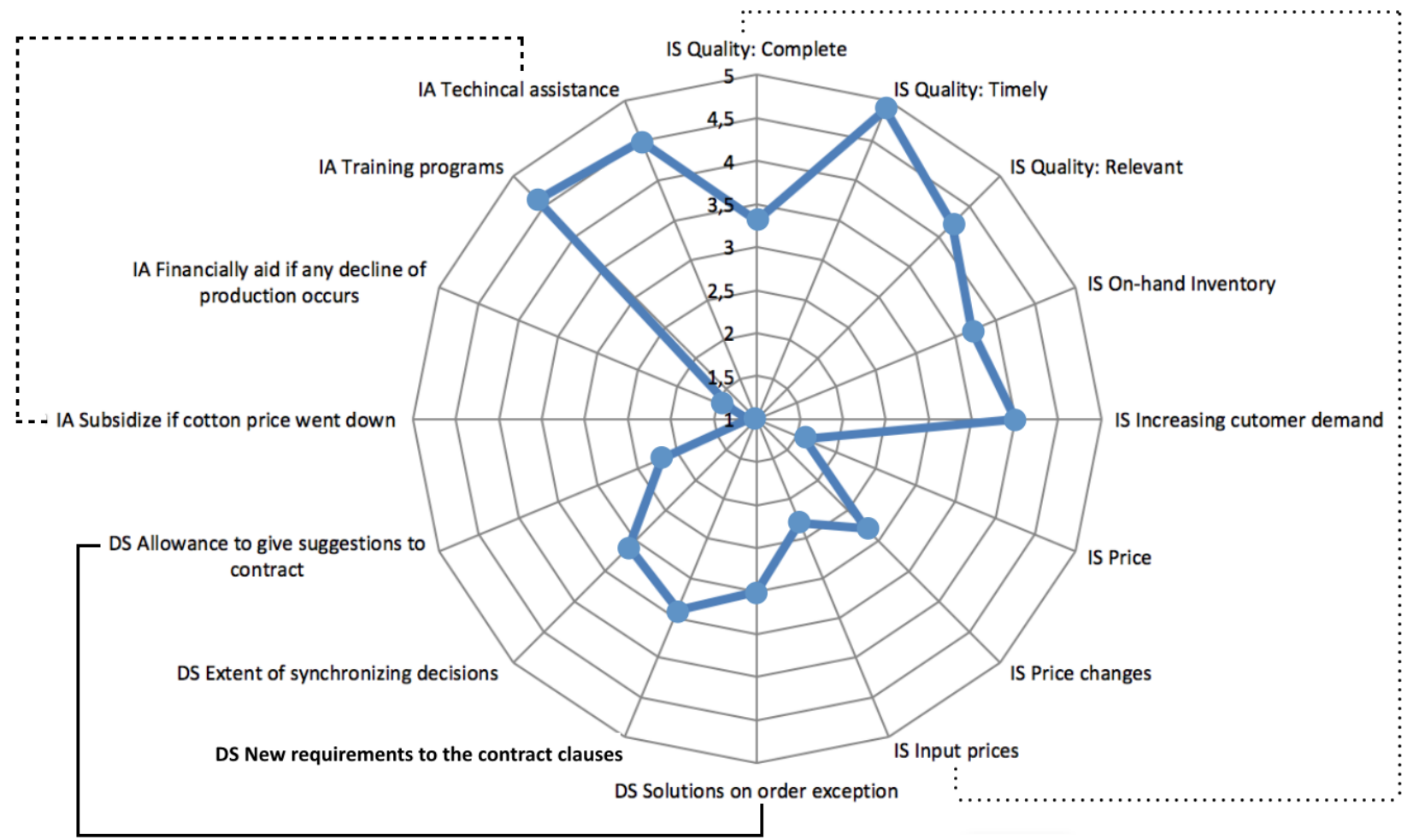

Figure 2. Dimensions of Supply Chain Collaboration: averages scores

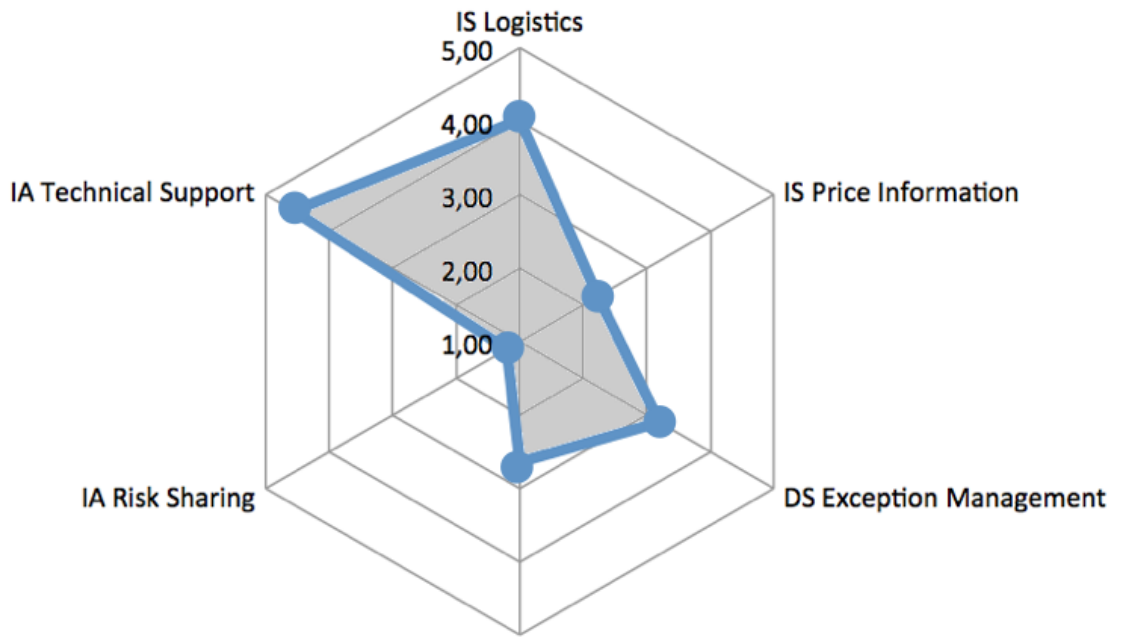

DS General Management 